\title{
Application of Geographical Information System in Animal Disease Surveillance and Control: A Review
}

\author{
Belege Tadesse ${ }^{1^{*}}$ and Abadi Amare ${ }^{1}$ \\ 1 Wollo University School of Veterinary Medicine, PO. Box. 1145, Dessie, Ethiopia; Phone: +251- \\ 931-201843 \\ *Corresponding author: Dr. Belege Tadesse; Email: tadessebelege@gmail.com
}

\section{Summary}

Animal disease patterns are changing because of climate change and there is a continuous occurrence of re-emerging and emerging types of diseases. So, new and modern tools are essential for monitoring and surveillance of these diseases. This review was done to give an insight on the applications of GIS in animal disease surveillance, reporting and control. Geographic information systems (GIS) provide the easy access, utilization and manipulation of geospatial information. The advantage of GIS is mapping the many different locations of farms and other facilities with animals on a single map which helps in better monitoring and surveillance. GIS also provides detailed information on disease forecasting, prediction of outbreaks, identification of disease clusters or hotspot, creation of buffer zones and to evaluate different strategies to prevent the spread of infectious diseases. Moreover, it provides an ideal condition for the collection of disease related data and their analyses in relation to population distribution, surrounding social and health services and the natural environmental conditions.

Keywords: Animal diseases; Control; GIS; Surveillance

\section{Introduction}

A GIS is a computerized information system in which user can capture, store, manipulate, analyse, manage, present, retrieve and share all types of spatial or geographic data. GIS is more user-friendly computer software which can show many different kinds of data on one map and enables users to analyse and interpret data on different locations plotted on map to understand relationships, patterns and trends (Bhatt and Janak, 2012). GIS has emerged as a tool with a multidisciplinary field with practical potential to be applied for any discipline handling data related to geographical locations (Norstrom, 2001). As 
GIS can map a variety of epidemiological information like morbidity, mortality, prevalence and incidence and geographical distribution of the diseases, it is very important in the veterinary field. GIS was first applied in veterinary medicine in 1994 for foot and-mouth disease epidemic (Sanson et al., 1994).

GIS helps the epidemiologists and public health professionals in the veterinary sector in analyzing associations between various locations, environment and disease pattern by providing different types of maps particularly for the spatial analysis (Cringoli et al., 2007; Sadkowska-Todys and Kucharczyk, 2012). GIS was applied for assessing the risk and the spatio-temporal distribution of plague in India (Rahelinirina et al., 2010) and other vector and waterborne diseases (Gubbels et al., 2012) in different countries.

Control of animal diseases requires epidemiological data about that particular disease. These data can be gathered using different systems like by using surveillance. Animal health surveillance is an essential tool to detect disease or infection, to monitor disease trends, to support claims for freedom from disease or infection, to provide data for use in risk analysis, and to substantiate the rationale for sanitary measures. Animal disease surveillance and monitoring are very important for improving disease analysis, early warning and controls the spread of diseases (Kshirsagar et al., 2013).

Molecular biology and genomics have given several sophisticated tools for rapid and confirmatory diagnosis of a particular disease. Disease surveillance and monitoring are also important to assess the status of a disease in a specific area and to implement effective prevention and control strategies (Deb and Chakraborty, 2012). GIS is a system used to display the information from research spatially for easy understanding (Deb et al., 2013; Dhama et al., 2013).

GIS is used as a powerful tool for displaying the regions of high disease prevalence and keeping an attention on control programs being carried out. GIS and Global Positioning System (GPS) provide an integrated approach enhancing the quality of data analysis and decision making to control the disease and its prevalence at regional or national level. Even if it has a number of uses there are a number of constraints to apply GIS easily. Although there are some reviews about the general use of GIS there is still a lack of organized information on the application of GIS in veterinary medicine and its challenges. Therefore, the objectives of this review are to indicate the applications of GIS in animal disease surveillance, reporting and control and its challenges. 


\section{Geographic Information System}

GIS is a potent tool for retrieval, interrogation, transformation and display of spatial data obtained from worldwide sources. GIS can act as a decision support system that involves the integration of all kinds of geo-referenced data (Burrough and McDonnell, 1998). GIS is used to map, analyze and interpret data related to some particular geographical location and disease distribution (Maguire, 1991; Alizadeha and Moghaddam, 2012). It has a range of powerful functions in addition to simple mapping, which include graphical analysis based on spatial location, statistical analysis and modeling. GIS has functions for solving problems (Cowen, 1988) such as the issue of emerging infections, to map and spatially analyze disease occurrences and distribution (Maguire, 1991).

GIS has an efficient capability of integrating different data in different format acquired from a wide range of data sources in to compatible format (Margonari et al., 2006). For example, the data to be used in a GIS may be available in the form of paper maps, tables of attributes, electronic files of maps and associated attribute data, aerial photos, satellite images and other sources in digital format (Margonari et al., 2006). These types of data can be displayed spatially using different tools on the GIS software. For example, using table join tool we can join and display spatially a disease incidence data stored in excel without geometry with other data that have a shape file. The commonly used GIS software's in veterinary medicine includes quantum GIS (QGIS) and arc GIS. The output of GIS provides a way to see the data or information in the form of maps, tables, diagrams, and so on (Aronoff, 1989). In veterinary epidemiology GIS can be applied for buffer generation, overlay operation, neighborhood analysis and spatial analysis (Bhatt and Janak, 2012; Margonari et al., 2006).

Overlay operations is operation in GIS that allow us to combine information from different vector files into a new file that is more tailored to our needs. By applying an overlay operation, specific changes occur at the spatial level as well as on the attribute level. Buffer generation calculates the distance from each cell to its nearest source. It is frequently used for applications, such as finding the nearest hospital, to calculate the distances from site of outbreak, to calculate the distances to major roads (Keith, 1997). 


\section{Data Sources of GIS}

The data for GIS can be derived from paper map, remote sensing and Global Positioning System (GPS).

\section{Paper map}

It is one of the most known sources of GIS, in which the information is plotted within a coordinate system that allows us to find its location. Mapping is a common technique of displaying the geographical distribution of disease and associated risk factors with the aid of digitizing maps (Jacoby et al., 2002). To digitize paper maps into a digital format, first, we must convert data from analog to digital format. Then, convert digital map into a scanned document and finally transform the digitized map from a source coordinate system to the geographic coordinate system using tics marks (Kumar, 2018).

\section{Remote sensing}

Remote sensing is the science and art of obtaining information about an item, area, or phenomenon through the analysis of data obtained by a device that isn't in physical contact with the object, area, or phenomenon under investigation. In such conditions, information is gathered in the form of digital photos of the earth's surface from airborne or satellite platforms and transforming them into maps (Lillesand et al., 2000). Usually, sensor devices are mounted on satellites or aircraft, or are installed at fixed coastal locations, that measure the electromagnetic radiation (EMR) that is emitted or reflected by features of the earth's surface, and which then convert the EMR into a signal that can be recorded and displayed as either numerical data or as an image (Lillesand et al., 2000).

\section{Global positioning system}

GPS is a satellite-based navigation system made of a network of twenty-four satellites placed into orbit that transmits precise microwave signals. The microwave signals latter allow the GPS receiver to determine its location, direction and time. Data from GPS can be utilized in association with existing spatial databases for a range of applications in spatial decision making (Jebara, 2007). 


\section{The Link of spatial data and GIS}

Spatial data are the backbone of GIS. In GIS the use of geo-coded data with coordinates is being promoted. The geo-referenced data are used as theme layers. Theme layers are spatial representation of analyzed data of elements of the same type. Moreover, they can be displayed singly or as overlay one above the other. Such data include an overhead projector that requires a geo-relational database and each of its features has linkage of attributed data for storage in a table and joining with the geographical data via a common identifier (ID). Therefore, each spatial data can be easily depicted as a map using GIS (Bhatt and Janak, 2012).

\section{Applications of GIS in Veterinary Medicine}

GIS has a wide-range of applications in veterinary medicine, such as outbreak notification, prevention and eradication of disease, disease surveillance, understanding and explaining disease dynamics and spreading patterns and correlation of disease trends with climate (Kuldeep et al., 2013).

\section{Application of GIS in Animal Disease Surveillance}

For a control strategy or to eradicate a disease, the exact disease status in that community is required to be known (Verma et al., 2008). GIS is one of the best tools used in various disease monitoring and surveillance programs today. GIS is being used to visualize disease foci, monitor newly infected or re-infected villages, and identify populations at risk, target cost-effective interventions, and monitor eradication efforts. GIS have been used in territorial cross-sectional and longitudinal parasitological surveys in order to experiment new applications to plan sampling protocols and to display the spatial distribution of infectious disease data to understand natural habitat and pattern of disease caused by infectious agents to animals (Rinaldi et al., 2004). GIS can be used to combine the information of computer maps with geographical data in order to support the spatial relationships along with patterns and trends in predicting future health status that need to be explored. Previously GIS was used to display the distribution of brown ear ticks in southern Africa, retrospectively comparing the eco-climatic favorability of particular locations for Rhipicephalus appendiculatus with the occurrence of East Coast fever (Lawrence, 1991).

Ethiop. Vet. J., 2021, 25 (1), 128-143 


\section{Formats of Disease Occurrence Data on a Map Using GIS}

The representation of disease incidence data can vary from simple point maps for cases and pictorial representation of counts (Lawson et al., 1999). The pattern and the presentation of spatial disease distribution can be divided into dot, diagram, choropleth and flow maps (Kistemann et al., 2002). Dot maps are able to show each health event with the resolution of a pair of coordinates, $x$ (longitude) and y (latitude). Choropleth maps are used to display mortality or morbidity rates for defined geographical units by coloring, shading or hatching, whereas flow maps are able to show the distribution dynamics of health events in time and space, and diagram maps provide added value to the presentation of quantitative data within a map (Kistemann et al., 2002).

The choice of map color is of great importance as it helps to transform numerical information into an informative map. It is also important to make a decision on the number of categories and the choice of cut-off points. In some cases, the primary aim of classification is to provide the reader the maximum available information, and the choice will depend on whether or not the scale is data-dependent. A clear distinction between different parts of the map should be appreciated by the reader (Smans and Estéve, 1992).

\section{Recording and reporting disease information using GIS}

GIS can be used to produce maps of disease incidence, prevalence, mortality, and morbidity on farm, region, or national levels. The information is more easily understood when visualized on a map. If the information is mapped at the farm level, value of data is maintained, and also small parts of a region can be visualized at the same time. The GIS was also incorporated in outbreak notification, for example in an eradication program of the Aujeszky's disease in North Carolina (McGinn et al., 1997). Geographical and disease incidence data were used as an input to notify the community for the occurrence of a particular disease in a specific area. GIS is one of the best tools for study and application of the Global Early Warning System (GLEWS) that formally brings together human and veterinary public health systems and application of environmental data for study of zoonotic and vector borne diseases (Kshirsagar et al., 2013). 


\section{Temporal distribution: Epidemic notification}

In case of an outbreak of an infectious disease, GIS can provide an excellent tool for identifying the location of the infected farms and at-risk farms within a specified area of the outbreak (Musekene and Tessema, 2009; Schimmer et $a l ., 2010)$. It has been used to strengthen data collection, management, and analysis, develop early warning systems, plan and monitor response programs, and communicate large volumes of complex information in a simple and effective way to decision makers and epidemiologists. After the infection sources are known buffer zones can be drawn around those farms and with a link to tables of the addresses of the farms at risk; the farms can be informed within a short time after a notified outbreak. Then at-risk farms will apply the appropriate preventive option. Buffer zones can also be generated around other risk areas or point sources, such as roads where infected cattle have been driven or around market places to limit spreading of the outbreak. Further, the maps can assist the field veterinarians to plan their work related to the current situation, and the veterinary authorities in how to handle a potential outbreak (Sanson et al., 1994, Schimmer et al., 2010). GIS can be used to display the magnitude and distribution of a specific disease within the different seasons of the year. This helps to differentiate risky seasons and to apply strategies that mitigate the distribution of the disease.

\section{Depicting the Spread of a Disease}

GIS has been extensively used in veterinary epidemiology for the study of different diseases, their etiology, association with ecology, transmission patterns, disease forecasting as well as the role of soil, vegetation types and other environmental factors in disease occurrence. Several viral, bacterial, parasitic and protozoal diseases have been studied to identify their spatial distribution, characteristics, and risk factors such as temperature, soil type, elevation, slope and land use. For example, Aujeszky's disease in US, fascioliasis in Brazil, bovine tuberculosis in New Zealand and UK, FMD in France, UK, Brazil and New Zealand; Campylobacteriosis in Sweden; Rift valley fever in US (Sorensen et al., 2000; Nygard et al., 2004; Musella et al., 2011; Konrad et al., 2012; Martins et al., 2012) spread were mapped using GIS. In Ethiopia, Yilma and Malone (1998) applied GIS to forecast model for strategic control of fasciolosis.

Integration of epidemiological data with the spatial and ecologic data plays important roles in analysis of variables responsible for disease transmission

Ethiop. Vet. J., 2021, 25 (1), 128-143 
(Konrad et al., 2012). Spatial analysis involves three basic steps; the preparation of an appropriate model, its proper visualization, and an exploratory data analysis, which range from simple map overlay to statistical models (Law et $a l ., 2004)$. Spatial analysis interprets and predicts population and inanimate objects movement from one place to another (Ord and Getis, 1995). For example, the movement of animals between wild and domestic areas is a form of spatial interaction, which has a crucial role in disease transmission. By accurately projecting these movements, high risk areas for disease transmission can be identified well in advance and thus intervention efforts can be planned and implemented accordingly.

\section{Disease Mapping and Geographical Information System}

One of the most useful functions of GIS in epidemiology is its use in disease mapping. When data are collected either routinely or through purposely-designed surveys, they are presented in tabular forms, which can be exploited for analytical usage. However, the reading and interpretation of such tabular data is often a laborious and time-consuming task and does not permit easy decision-making (Paolino et al., 2005). However, if the collected data is depicted on the map using GIS it will be easily understood by the readers.

Disease mapping methods were first used for communicable diseases in an attempt to identify the sources of infection and to describe the rate of spreading of disease (Paolino et al., 2005). Mapping of chronic diseases started with the recognition that environmental factors play an essential role in their etiology. Geographical epidemiological studies, in which health and environmental exposure data are analyzed in fine geographical detail, represent an important new approach (Paweska et al., 2008). The aims and purposes of disease mapping are: to describe the spatial variation in disease incidence for the formulation of etiological hypotheses; to identify areas of unusually high risk in order to take preventive action; to provide a reliable map of disease risk in a region to allow better resource allocation and risk assessment (Pfeiffer, 2002; Rinaldi et al., 2005).

\section{Geographical Information System for Planning of disease Control Strategies}

GIS technology has many features which make it ideal for use in animal disease control, including the ability to store information relating to demographic 
and causal factors and disease incidence on a geographical background, and a variety of spatial analysis functions. The neighborhood analysis function can be used to identify all adjacent farms to an infected farm. It is a function that identifies all adjacent features with a certain criterion to a particular feature. Contact patterns such as common use of grasslands, watering points or sources of purchasing etc. could be visualized with a so-called spider diagram. This could provide insight into the possibility of transmission of infectious diseases between herds. In the planning of eradication of diseases, GIS has the capability to perform superimpose analysis to find high or low risk areas for diseases which depend on geographical features or conditions related to the geography (Kamiya, 2007). For example, previous studies on trypanosomiasis (Rogers, 1991); theileriosis (Lessard et al., 1990) and dengue fever (Alzahrani et al., 2013), shows how to use GIS to plan eradication of diseases depending on habitats of vectors or wild animal population.

Emerging and re-emerging diseases pose a major threat in various parts of the world, partly due to climatic changes, as well as the recent spread of several contagious and vector-borne diseases into new or previously controlled areas (Rogers and Randolph, 2006). The current capabilities of GIS (especially collection of satellite data with respect to spatio-temporal and spectral resolution) make it appropriate for epidemiological research (Abdullayev et al., 2012) and mapping vector-borne re-emerging diseases (Bergquist, 2011), including schistosomiasis (Yang et al., 2006), malaria as well as leishmaniasis and dirofilariasis (Genchi et al., 2009). The GIS also helped researchers to identify areas having high prevalence and risk groups apart from identifying areas having shortage of resources to make decisions to allocate resources in case of vector borne diseases. As a result, based on the information obtained any responsible authority can plan the best control option.

\section{Challenges for the application of GIS}

GIS can be used in different studies including marketing studies, telecommunications, and location of restaurants, museums and hospitals; in establishing maps of animal population density by species or maps of vegetation coverage change; in locating forests, rivers, and mountains; indicating disease outbreak sites (Jebara, 2007). However, the application of GIS in the routine activities of the majority of developing countries including Ethiopia is not optimal. This is mainly due to lack of awareness by decision-makers; low stock of base data; uncertain data discovery, access and exchange mechanisms; and insufficient 
human and technical resources (Melese, 2002). One of the challenges in GIS science and many other fields is the efficient and economical processing of massive data sets (Babalobi et al., 2005).

\section{Limitations and strength of GIS}

The strength of GIS relies on its ability to merge geographic information with the information of veterinary medicine. GIS can allow viewing, questioning, understanding, visualizing and interpreting the data into numbers of ways which will reveal relationships, trends and patterns in the form of globes, maps, charts and reports (Babalobi et al., 2005). Many factors undermine the ability of a developing country to use GIS effctively. However, the efforts applied to solve these challenges leads the creation of options, collectively known as spatial data infrastructures (SDI), which flourishes a country's ability to use geo-information effectively (Bolstad, 2016).

Although GIS has several advantages, it has its own limitations. For example, it is expensive and requires enormous data inputs amount that are needed to be practical for some other tasks. GIS layers might lead to some costly mistakes once the property agents are to interpret the GIS map or the design of the engineer around the utility lines of the GIS. There might be failures initiating additional efforts in order to fully implement the GIS but there might be large benefits to anticipate as well. A GIS system stores extremely large amounts of data at any given time. This may create problems when it comes to analysis due to the complexity of the data and the risk of generalization. GIS data require complex overlay operations that are difficult to achieve especially when the personnel involved are not properly trained (Babalobi, 2007).

\section{Geographical Information System in Ethiopia}

Even if GIS has paramount importance in the surveillance, monitoring, control and eradication of particular diseases from a certain locality; still it is not well used in Ethiopia. This is mainly due to a lack of training for personnel, the difficulty of accessing good quality data, and cost indicated to produce quality data (Mesele, 2002). Only some researchers used GIS to show the spatiotemporal distribution of some diseases. For example, Fentie et al. (2017) used GIS to show the spatio- temporal distribution of sheep and got pox outbreaks in Amhara region during the year 2010-2014. Molla et al. (2017) also used GIS to show both the spatial and temporal distribution of Lumpy skin disease in 
cattle in Ethiopia. The global risk of the major arboviral diseases transmitted by Aedes aegypti and Aedes albopictus were mapped by Leta et al. (2017) by identifying areas where the diseases are reported, either through active transmission or travel-related outbreaks. GIS was also applied in Ethiopia for strategic control of fasciolosis, malaria management, and abattoir construction site selection (Yilma and Malone, 1998; Craig et al., 1999). The Spatial distribution of incidence of foot and mouth disease outbreaks in Amhara region of Ethiopia in the period 1999 to 2016 was mapped by Aman et al. (2020). Kumsa (2015) used GIS, remote sensing and GPS to show land use/ land cover change of Jarmet wetland (western Ethiopia) and its surrounding environment over years as a response to population growth. GIS were also applied on climate change and desertification, land use planning and monitoring, municipal application, hydrology surveys, soil surveys, geological surveys, and demography (Melese, 2002).

In Ethiopia there are many economically important diseases that are reportable to the OIE. In order to apply strategies that limit the spreading of these diseases and to create disease free compartments, application of GIS is very important.

\section{Conclusions and recommendations}

GIS is competent technology for collecting, processing and presenting data pertaining to disease incidences, to help design control and preventive approaches. GIS can add a significant value to epidemiological data that lacks a spatial component. It adds value to enhance the usefulness of displayed information to make better informed decision. GIS is believed to play an increasingly crucial role to survey, monitor and assess infectious diseases at national or international levels and to aid in rapid controlling of economically important diseases. Moreover, GIS has the ability to link spatial and non-spatial data which facilitates powerful analysis of spatial and temporal disease distribution and related issues. In veterinary science using GIS it is possible and easy to draw the maps and visualize possible temporal and spatial risk factors, outbreak distribution and areas at risk of developing the outbreak. Using GIS, the surveillance and monitoring system can be strengthened and the collection, storage, management and reporting of data can be improved to enable policy makers take better informed decision. In the developed world, the application of GIS in the field of veterinary epidemiology is increasing recently, but its application is at low level in developing countries that needs to be strengthened. Thus,

Ethiop. Vet. J., 2021, 25 (1), 128-143 
training of veterinary epidemiologists and other veterinary experts about application of GIS for disease surveillance and monitoring programs should be considered for the optimal use of this technology.

\section{References}

Abdullayev, R., Kracalik, I., Ismayilova, R., Ustun, N., Talibzade, A. and Blackburn, J.K. 2012. Analyzing the spatial and temporal distribution of human brucellosis in Azerbaijan (1995 - 2009) using spatial and spatiotemporal statistics. BMC Infect. Dis., 12, 185-196.

Alizadeha, H., and Moghaddam, S.E., 2012. An application of GIS in veterinary, wild world and zoonosis disease in order to have a healthy population and crisis management. Info. Technol. Com. Sci., 1, 837-840.

Alzahrani, A.G., Al Mazroa, M.A., Alrabeah, A.M., Ibrahim, A.M., Mokdad, A.H. and Memish, Z.A. 2013. Geographical distribution and spatio-temporal patterns of dengue cases in Jeddah Governorate from 2006-2008. Trans. R. Soc. Trop. Med. Hyg., 107(1), 23-29.

Aman, E., Molla, W., Gebreegizabher, Z. and Jemberu, W.T. 2020. Spatial and temporal distribution of foot and mouth disease outbreaks in Amhara region of Ethiopia in the period 1999 to 2016. BMC Vet. Res., 16, 185-192.

Aronoff, S.1989. Geographic information systems: A management perspective. Geocar. Inter., 4 (4), 58-61.

Babalobi, O., Onyeka, L. and Ogundipe, G. 2005. Towards an increasing awareness and use of veterinary geo-information technologies in Nigeria: A review. Vom. J. Vet. Sci., 1, 45-51.

Babalobi, O.O. 2007. Veterinary geographic information systems applications in Nigeria: limitations, challenges and needs. Vet. Italia., 43(3), 491-499.

Bergquist, R.2011. New tools for epidemiology: a space odyssey. Mem. Inst. Oswaldo. Cruz., 106(7), 892-900.

Bhatt, B. and Janak, J. 2012. GIS in Epidemiology: Applications and Services. Nat. J. Comm. Med.; 3(2), 259-263.

Bolstad, P. 2016. GIS fundamentals: A first text on geographic information systems. $4^{\text {th }}$ ed). Eider Press, Minnesota, USA, Pp. 15-22.

Burrough, P.A. and McDonnell, RA.1998. Principles of Geographical Information Systems, (1st ed). Oxford University Press Inc., New York, USA, Pp. 35-57.

Cowen, D.J. 1988. GIS versus CAD versus DBMS: What are the differences? Photogrammetric Eng. Rem. Sens., 54, 1551-1554. 
Craig, M.H., Snow, R. and le Sueur, D. 1999. A climate-based distribution model of malaria transmission in sub-Saharan Africa. Parasitol. Today, 15(3), 105-111.

Cringoli, G., Rinaldi, L., Musella, V., Veneziano, V., Maurelli, M.P., Di Pietro, F., Frisiello, M. and Di Pietro, S. 2007. Geo-referencing livestock farms as tool for studying cystic echinococcosis epidemiology in cattle and water buffaloes from Southern Italy. Geo. spat. Hlth., 2(1), 105-111.

Deb, R. and Chakraborty, S. 2012. Trends in veterinary diagnostics. J. Vet. Sci. Tech., 3, e103.

Deb, R., Chakraborty, S., Veeregowda, B.M., Verma, A.K., Tiwari, R. and Dhama, K., 2013. Monoclonal antibody and its use in the diagnosis of livestock diseases. Adv. Biosci. Biotech., 4, 50-62.

Dhama, K., Chakraborty, S., Kapoor, S., Tiwari, R., Kumar, A., Deb, R., Rajagunalan, S., Singh, R., Vora, K. and Natesan, K. 2013. One world, one health - Veterinary perspectives. Adv. Anim. Vet. Sci., 1(1), 5-13.

Fentie, T., Fenta, N., Samson L., Molla, W., Ayele, B., Teshome, Y., Negatu, S. and Achenef, A. 2017. Sero-prevalence, risk factors and distribution of sheep and goat pox in Amhara Region, Ethiopia. BMC Vet. Res., 13, 385.

Genchi, C., Rinaldi, L., Mortarino, M., Genchi, M. and Cringoli, G. 2009. Climate and Dirofilaria infection in Europe. Vet. Parasitol., 163, 286-292.

Gubbels, S.M., Kuhn, K.G., Larsson, J.T., Adelhardt, M., Engberg, J., Ingildsen, P., Hollesen, L.W., Muchitsch, S., Molbak, K. and Ethelberg, S. 2012. A water-borne outbreak with a single clone of Campylobacter jejuni in the Danish town of Koge in May 2010. Scand. J. Infect. Dis., 44(8), 586-594.

Jacoby, S., Smith, J., Ting, L. and Williamson, I., 2002. Developing a common spatial data infrastructure between State and Local Government-An Australian case study. Int. J. Geo. Infor. Sci., 16(4), 305-322.

Jebara, K.B. 2007. The role of Geographic Information System (GIS) in the control and prevention of animal diseases. Conf. OIE 2007, 175-183.

Kamiya, M. 2007. Collaborative control initiatives targeting zoonotic agents of alveolar echinococcosis in the northern hemisphere. J. Vet. Sci., 8(4), 313-321.

Keith, C. 1997. Getting Started with Geographic Information Systems, (4 ${ }^{\text {th }}$ ed). Upper Saddle River, NJ: Prentice Hall, Pp. 34-44.

Kistemann, T., Dangendorf, F., and Schweikart, J., 2002. New perspectives on the use of Geographical Information Systems (GIS) in environmental health sciences. Int. J. Hyg. Environ. Hlth., 205(3), 169-181.

Konrad, S.K., Zou, L. and Miller, S.N. 2012. A geographical information system-based web model of arbovirus transmission risk in the continental United States of America. Geo. spat. Hlth., 7(1), 157-159. 
Kshirsagar, D.P., Savalia, C.V., Kalyani, I.H., Kumar, R. and Nayak, D.N. 2013. Disease alerts and forecasting of zoonotic diseases: an overview, Vet. World.; 6(11), 889-896.

Kuldeep, D., Verma, A., Ruchi, T., Sandip, C., Kranti, V., Kapoor, S., Rajib, D., Kaliaperumal, K., Singel, R., Munir, M., and Senthil Kumar, N., 2013. A perspective on applications of Geographical Information System (GIS): An advanced tracking tool for disease surveillance and monitoring in veterinary epidemiology. Adv. Anim. Vet. Sci., 1, 14-24.

Kumar, K. 2018. Identification of library location through Arc GIS software: Geographical information system. I. J. Agri. L. Inf. Serv., 34(3), 227.

Kumsa, A. 2015. GIS and remote sensing-based analysis of population and environmental change: the case of Jarmet wetland and its surrounding environments in western Ethiopia. MSc Thesis, Addis Ababa University, Department of geography and environmental studies. Addis Ababa, Ethiopia, Pp.56-79.

Law, D.C.G., Serre, M.L., Christakos, G., Leone, P.A. and Miller, W.C. 2004. Spatial analysis and mapping of sexually transmitted diseases to optimize intervention and prevention strategies. Sex Transm. Infect., 80(4), 294- 299.

Lawrence, J.A. 1991. Retrospective observations on the geographical relationship between Rhipicephalus appendiculatus and East Coast fever in southern Africa. Vet. World, 128(8), 180-183.

Lawson, A.B., Böhning, D., Biggeri, A., Lesaffre, E. andViel, J.F. 1999. Disease mapping and its uses. In Lawson A., Biggeri, A., Böhning, D., Lesaffre, E., Viel, J.F. and Bertollini, R. (Eds.), Disease mapping and risk assessment for public health. John Wiley and Sons Ltd; West Sussex, UK, Pp 3-13.

Lessard, P., L'Eplattenier, R.L., Norval, R.A.I., Kundert, K., Dolan, T.T., Croze, H., Walker, B., Irvin, AD. And Perry, BD. 1990. Geographical information systems for studying the epidemiology of cattle diseases caused by Theileria parva. Vet. Rec., 126, 255-262.

Leta, S., Beyene, T.J., De Clercq, E.M., Amenu, K., Moritz, U.G., Kraemer, and Crawford W. R. 2017. Global risk mapping for major diseases transmitted by Aedes aegypti and Aedes albopictus. Int. J. Infect. Dis., 67 (2018), 25-35.

Lillesand, T.M., Kiefer, R.W. and Chipman, J. 2000. Remote sensing and image interpretation. ( $6^{\text {th }}$ ed). John Willey and Sons, New York. USA, Pp. 736.

Lillesand, T.M., Kiefer, R.W. and Chipman, J. 2007. Remote sensing and image interpretation, $6^{\text {th }}$ edition, Wiley, Chichester, UK, Pp. 112-122.

Maguire, D.J. 1991. An overview and definition of GIS. In: Maguire, D.J., Goodchild, M.F. and Rhind, D.W. (Eds), Geographical Information Systems, $2^{\text {nd }}$ edition, Vol. 1, Principles. Longman Scientific and Technical, Harlow, UK, Pp. 9- 20. 
Margonari, C., Freitas, C.R., Ribeiro, R.C., Moura, A.C.M, Timbó, M., Gripp, A.H., Pessanha, J.E. and Dias, E.S. 2006. Epidemiology of visceral leishmaniasis through spatial analysis, in Belo Horizonte municipality, state of Minas Gerais, Brazil. Mem. Inst. Oswaldo. Cruz., 101(1), 31-38.

Martins, I.V., de Avelar, B.R., Pereira, M.J. and da Fonseca, A.H. 2012. Application of a geographical information system approach for risk analysis of fascioliasis in southern Espirito Santo state, Brazil. Geospat. Hlth., 6(3), S87-S93.

McGinn, T.J., Cowen, P., Wray, D.W. 1997. Integrating a geographic information system with animal health management. Epid. et Santé Anim.,12, 31-32.

Melese, A. 2002. Application of GIS for urban planning in Ethiopia with particular reference to abattoir site suitability analysis for Kulito town: An Exploration. MSc Thesis, Addis Ababa University, School of information studies for Africa, Addis Ababa, Ethiopia, Pp 48-53.

Molla, W., de Jong M.C.M. and Frankena, K. 2017. Temporal and spatial distribution of Lumpy Skin Disease outbreaks in Ethiopia in the period 2000 to 2015. BMC Vet. Res., 13, 310-318.

Musekene, J.N. and Tessema, A. 2009. Spatial distribution of diarrhoea and microbial quality of domestic water during an outbreak of diarrhoea in the Tshikuwi community in Venda. South Africa. J. Hlth. Pop. Nutr., 27(5), 652-629.

Norstrom, M., 2001. Geographical information system (GIS) as a tool in surveillance and monitoring of animal diseases. Acta Vet. Scand., 94, 79- 85.

Nygard, K., Andersson, Y., Røttingen, J.A., Svensson, A., Lindbäck, J., Kistemann, T. and Giesecke, J. 2004. Association between environmental risk factors and Campylobacter infections in Sweden. Epidemiol. Infect., 132(2), 317- 325.

Musella, V., Catelan, D., Rinaldi, L., Lagazio, C., Cringoli, G. and Biggeri, A. 2011. Covariate selection in multivariate spatial analysis of ovine parasitic infection. Prev. Vet. Med., 99(2-4), 69-77.

Ord, K. and Getis, A. 1995. Local spatial autocorrelation statistics: distributional issues and an application. Geog. Anal., 24, 286-306.

Paolino, L., Sebillo, M., and Cringoli, G., 2005. Geographical information systems and on-line GIS services for health data sharing and management. Parasitol., 47(1), 171-175.

Paweska, J., Blumberg, L., Weyer, J., Kemp, A., Leman, P., Archer, B., Nkosi, S. and Swanepoel, R. 2008. Rift Valley fever outbreak in South Africa. NICD-NHLS Commun. Dis. Survei. Bullet., 6(2), 1-2.

Pfeiffer, D.U. 2002. Veterinary Epidemiology-An Introduction. 1st edition, Royal Veterinary College, United Kingdom, Pp 62. 
Rahelinirina, S., Duplantier, J.M., Ratovonjato, J., Ramilijaona, O., Ratsimba, M. and Rahalison, L. 2010. Study on the movement of Rattus rattusand evaluation of the plague dispersion in Madagascar. Vector Borne Zoonotic Dis., 10, 77-84.

Rinaldi, L., Cascone, C., Sibilio, G., Musella, V., Taddei, R. and Cringoli, G. 2004. Geographical Information Systems and remote sensing technologies in parasitological epidemiology. Parasitol., 46(1-2), 71-4.

Rinaldi, L., Fusco, G., Musella, V., Veneziano, V., Guarino, A., Taddei, R. and Cringoli, G. 2005. Neospora caninum in pastured cattle: determination of climatic, environmental, farm management and individual animal risk factors using remote sensing and geographical information systems. Vet. Parasitol., 128(3-4), 219-230.

Rogers, D.J. 1991. Satellite imagery tsetse and trypanosomiosis in Africa. Prev. Vet. Med., 11, 201-220.

Rogers, D.J. and Randolph, S.E. 2006. Climate change and vector-borne diseases. Adv. Parasitol., 62, 345-381.

Sadkowska-Todys, M. and Kucharczyk, B. 2012. Rabies in Poland in 2010. Przegl. Epidemiol., 66(2), 297-302.

Sanson, R.L., Ster, M.W. and Morris, R.S. 1994. Interspread- A spatial stochastic simulation model of epidemic foot-and-mouth disease. The Kenyan Vet., 18(2), 493-495.

Schimmer, B., Ter Schegget, R., Wegdam, M., Züchner, L., de Bruin, A., Schneeberger, P.M., Veenstra, T., Vellema, P. and van der Hoek, W. 2010. The use of a geographic information system to identify a dairy goat farm as the most likely source of an urban Q-fever outbreak. BMC Infect. Dis., 10, 69.

Smans, M. and Estéve, J., 1992. Practical approaches to disease mapping. In Elliot P, Cuzick J, English D and Stern R, (Eds), Geographical and Environmental Epidemiology: Methods for Small-Area Studies. Oxford: Oxford Press, UK, Pp139-150.

Sorensen, J.H., Mackay, D.K., Jensen, C.O. and Donaldson, A.I. 2000. An integrated model to predict the atmospheric spread of foot-and-mouth disease virus. Epidemiol. Infect., 124(3), 577-590.

Verma, A.K., Pal, B.C., Singh, C.P., Jain, U., Yadav, S.K. and Mahima 2008. Studies of the outbreaks of foot-and-mouth disease in Uttar Pradesh, India, between 2000 and 2006. Asian J. Epidemiol., 1(2), 40-46.

Yang, G.J., Vounatsou, P., Tanner, M., Zhou, X.N. and Utzinger, J. 2006. Remote sensing for predicting potential habitats of Oncomelania hupensis in Hongze, Baima and Gaoyou lakes in Jiangsu province, China. Geo. Spat. Hlth., 1, 85-92.

Yilma, J. and Malone, J. 1998. A geographic information system forecast model for strategic control of fasciolosis in Ethiopia. Vet. Parasitol., 78(2), 103-127. 